\title{
Mengembangkan Self Regulation Mahasiswa agar dapat Mengikuti Pembelajaran Online Lebih Produktif
}

\author{
Lucia Hernawati ${ }^{1}$, Praharesti Eriany ${ }^{2}$ \\ Fakultas Psikologi Universitas Katolik Soegijapranata, Semarang \\ herna@unika.ac.id ${ }^{1}$ \\ praharesti@unika.ac.id ${ }^{2}$
}

\begin{abstract}
Abstrak-Tujuan pelatihan ini untuk meningkatkan kemampuan mahasiswa mengelola dirinya (self regulation/SRL) agar dapat mengikuti pembelajaran online dengan lebih produktif. Dua puluh empat mahasiswa fakultas Psikologi Unika Soegijapranata berpartisipasi dalam pelatihan ini. Sebelum pelaksanaan, peserta diminta untuk mengisi skala yang berisi aitem tentang SRL sebagai data pre test. Pelatihan diselenggarakan dalam 4 minggu dengan durasi waktu 120 menit setiap sesi yang akan disampaikan secara daring dengan menggunakan platform google meet. Setiap sesi pelatihan diikuti dengan pemberian tugas rumah yang harus disusun dan dipraktekkan. Di akhir sesi akan diberikan skala SRL yang sama sebagai data post test. Materi pelatihan mencakup : (1)Penyampaian materi tentang SRL, menetapkan goal setting dan latihan untuk menyusun aktivitas harian selama satu hari; (2) Pemberian materi tentang kesiapan diri sebelum-saat dan setelah mengikuti pembelajaran online dan time management; (3) Evaluasi pelaksanaan dari perencanaan yang telah dilakukan selama 3 hari; (4) Evaluasi pelaksanaan aktivitas yang diselenggarakan selama 5 hari.Lembar informed consent diberikan untuk memastikan kesediaan peserta untuk mengikuti keseluruhan pelatihan. E-sertifikat diberikan pada peserta yang mengikuti seluruh rangkaian pelatihan. Data pre test dan post test dianalisis dengan menggunakan statistik parametrik analisis Uji Paired T-Test. Hasilnya menunjukkan nilai $t=1.707$ (p>0.05) yang menunjukkan tidak ada perbedaan antara sebelum dan setelah mengikuti pelatihan. Sekalipun demikian, secara lisan peserta menyampaikan setelah mengikuti pelatihan ini lebih mampu mengelola waktunya dengan lebih prduktif, menetapkan goal setting, membuat perencanaan aktivitas yang realistis dengan menimbang aktvitas lain yang harus dilakukan seperti waktu untuk istirahat, family time dan me time.
\end{abstract}

Kata kunci ; Pelatihan Self Regulation, Pembelajaran Online, Mahasiswa
Abstract-The purpose of this training is to improve students ability to self-regulate (SRL) which enables them to participate in online learning more productively. Twenty-four students of the Psychology Faculty of Soegijapranata University participated in this training. Prior to the training, the participants were asked to fill out a scale containing items about SRL as pre-test data. The training was held online with google meet in 4 weeks with a duration of 120 minutes for each session. Each session was followed by home assignment which

should be compiled and practiced. At the end of the session, the same SRL scale was given as the post-test data. The training materials include: (1) SRL, goal settings and training to organize one day daily activities; (2) self-preparation before and after participating in online learning and time management; (3) Evaluation of the 3 days implementation of the planning; (4) Evaluation of the 5 days implementation of the activities. An informed consent form was provided to ensure participants' willingness to participate in the whole training. The pre-test and post-test data were analyzed using parametric statistics analysis of the Paired T-Test. The results show that the value of $t=1.707(p>0.05)$ which indicates that there is no difference between before and after training participation. Even so, the participants verbally said that after attending this training they were able to manage their time more productively, set goal settings, make realistic activity plans by considering other activities that must be done such as time to rest, family time and me time.

Keywords ; Self- Regulation Training, Online Learning, Students

\section{PENDAHULUAN}

Salah satu dampak dari pandemi covid-19 di Indonesia adalah munculnya perubahan sistem pendidikan. Bila sebelumnya pembelajaran di semua jenjang pendidikan dilakukan secara tata muka namun pada masa pandemi ini tidak bisa lagi dilakukan. Pembelajaran secara tatap muka 
digantikan dengan pembelajaran yang dilakukan secara daring (online). Sejak bulan Maret 2021 pembelajaran dilakukan secara online. Butuh adaptasi dari dosen maupun mahasiswa terkait dengan kondisi tersebut. Kurangnya kesiapan dari kedua belah pihak memunculkan beragam masalah [1].

Hingga saat ini pandemi covid sudah berjalan 1 tahun namun belum ada tanda-tanda akan berakhir. Kegiatan perkuliahan pada masa pandemi dan sebelum pandemi pada umumnya tidak sama. Sebelum pandemi, perkuliahan dilakukan di kelas. Dosen berperan aktif mengelola kelas sehingga mahasiswa merasa nyaman menerima semua materi perkuliahan. Demikian pula teman-teman di kelas saling dukung untuk menyelesaikan berbagai tugas dari dosen. Namun pada saat pandemi seperti sekarang ini, perkuliahan dilakukan secara online, mahasiswa hanya berhadapan dengan layar laptop. Bertemu dengan dosen dan teman-teman di ruang cyber, google meet, zoom saat perkuliahan online terasa tidak nyata. Apa yang dilakukan mahasiswa saat perkuliahan tidak ada yang mengontrol. Sekarang mahasiswa secara pribadi harus bertanggung jawab mengkoordinir semua kegiatannya sendiri. Dukungan dari dosen dan teman-teman ada namun terasa minimal. Pada perkuliahan sebelum pandemi motivasi eksternal muncul dari berbagai penjuru sekarang motivasi internal dituntut mendominasi [2]

Berdasarkan wawancara singkat dengan mahasiswa semester 2 dan 4 Fakultas Psikologi Unika Soegijapranata yang dilaksanakan pada tanggal 11 Maret 2021 secara online diperoleh informasi bahwa permasalahan utama yang dialami mahasiswa adalah kurang mampu mengelola diri (self regulation kurang berkembang). Dampaknya saat pembelajaran online dan mengerjakan tugas-tugas dari dosen mereka malas dan mengantuk. Disamping itu mahasiswa tidak mampu mengelola waktu produktif secara maksimal. Banyak tugas-tugas individual maupun kelompok dari dosen dikerjakan semalam sebelum dikumpulkannya. Akibatnya kualitas tugas tidak maksimal dan tubuh merasa tidak sehat (sakit kepala). Kompleksitas permasalahan yang muncul sebagai dampak dari pembelajaran online yang menuntut mahasiswa memiliki kemampuan untuk bisa mengelola dirinya (self regulation) agar lebih produktif. Bila mahasiswa memiliki kemampuan self regulation yang memadai maka mahasiswa dapat mengupayakan diri untuk menyatukan pikiran, perasaan dan perilaku yang direncanakan secara siklis dalam mencapai apa yang diinginkan [3]

Mahasiswa yang berada pada fase dewasa awal membutuhkan bantuan untuk mampu mengembangkan kemampuan self regulation nya. Mahasiswa pada umumnya berada pada rentang usia 19-24 tahun yang merupakan fase peralihan dari remaja akhir menuju dewasa awal. Pada fase perkembangan ini mahasiswa perlu dibantu agar semakin mampu (a) mengatur berbagai aktivitas, minat, pembuatan prioritas; (b) melakukan adaptasi dengan kehidupan orang dewasa; (c)memandang hidup secara ideal; (d) melakukan pekerjaan secara mandiri; (e) memiliki komitmen untuk bertanggung jawab; (f) memasuki perubahan nilai-nilai yang dianut oleh orang dewasa; (h) melakukan penyesuaian diri dengan cara hidup baru dalam masyarakat; (i) memasuki masa kreatif [4], [5]

Dengan demikian perguruan tinggi perlu membuat program pelatihan yang dapat membantu mahasiswa dapat mengelola dirinya (meningkatkan kemampuan self regulation) agar mahasiswa dapat mengikuti pembelajaran online dengan lebih produktif. Bila mahasiswa dapat mengembangkan self-regulation nya diharapkan mampu mengatur target akademik yang ingin dicapai, membuat strategi untuk mencapai target akademik yang telah ditetapkan, membuat perencanaan kegiatan dalam perilaku, monitoring pelaksanaan kegiatan untuk mencapai target, membuat evaluasi terhadap perencanaan dan pelaksanaannya dalam situasi riil. Mengembangkan selfregulation secara berkesinambungan selama masa perkuliahan akan membentuk karakter kepribadian yang dapat dilanjutkan setelah kuliah S1 usai. Pengembangan self regulation meliputi tiga tahap yaitu tahap satu: fase persiapan dengan target menetapkan goal setting dan membuat perencanaan untuk mencapai goal setting; tahap dua: monitoring, berupa aktivitas menjalankan perencanaan untuk mencapai goal setting; tahap tiga: evaluasi berupa kegiatan membuat evaluasi terhadap perencanaan dan pelaksanaan aktualisasi perencanaan [6]. Pada saat mahasiswa mengembangkan self-regulation maka selfmotivation mahasiswa dikuatkan untuk mencapai goal setting yang telah ditetapkan. Selanjutnya di fase monitoring dalam menjalankan strategi mencapai goal setting, dikuatkan self-control dengan melakukan selfinstruction, imagery, attention focusing dan task strategy. Semua pelaksanaan pembuatan rencana pencapaian goal setting dan realisasinya selanjutnya dievalusi. Pada fase evaluasi, dilakukan self-judgement dan self reaction untuk pembuatan perencanaan selanjutnya.

Salah satu kelebihan pelatihan self regulation adalah bersifat flesibel, tidak baku seperti self management. Mahasiswa dapat menggunakan self regulationnya secara intensif untuk merancang dan mengaktualisasikan berbagai perilaku dalam mencapai suatu tujuan tertentu dalam mengembangkan dirinya [7]; [8]; [9] .Namun ada kalanya mahasiswa secara sengaja melakukan perilaku yang tidak sejalan dengan tujuan yang telah ditetapkan atau malah bertentangan (loss based selection). Bila hal itu terjadi maka setelah melakukan kegiatan yang tidak sejalan atau bertentangan tersebut selanjutnya mahasiswa dapat melakukan kompensasi untuk kembali berperilaku sesuai dengan perencanaan awal. Hal ini banyak dilakukan pada mahasiswa yang berada pada fase remaja hingga dewasa 
awal. Karena pada fase ini pada umumnya mahasiswa melakukan orientasi dan pengembangan diri di berbagai hal.

Tujuan kegiatan ini adalah untuk meningkatkan kemampuan self regulation mahasiswa agar dapat mengikuti pembelajaran online lebih produktif.

Manfaat teoretis kegiatan ini dapat mengembangkan teori psikologi pendidikan dan psikologi perkembangan khususnya yang berkaitan dengan self-regulation dan pembelajaran online. Sedangkan manfaat praktisnya dapat memberi informasi bagi pengelola perguruan tinggi dan mahasiswa khususnya tentang pelatihan self regulation mahasiswa agar dapat lebih produktif dalam mengikuti pembelajaran online.

\section{METODOLOGI}

Pelatihan self regulation dilaksanakan untuk membantu mahasiwa semester 2 dan 4 fakultas Psikologi UNIKA Soegijapranata agar dapat mengikuti pembelajaran online lebih produktif. Adapun pelaksanaannya melalui beberapa tahapan sebagai berikut:

A. Persiapan

1. Menyiapkan materi pelatihan meningkatkan pengelolaan diri (self regulation) agar dapat mengikuti pembelajaran online lebih produktif yang akan disampaikan 4 sesi. Dan menyiapkan skala pengukuran self regulation.

2.Melakukan rekrutmen peserta pelatihan dari mahasiswa Angkatan 2019 dan 2020 fakultas Psikologi UNIKA Soegijapranata dengan kriteria: Memiliki masalah dalam mengikuti pembelajaran online karena kemampuan self- regulation yang kurang memadai; mempunyai kemauan untuk membentuk kebiasaan baru agar dapat mengikuti pembelajaran online; memiliki komitmen untuk mengaplikasikan semua materi yang diperoleh pada perilaku riil sehingga dapat terbentuk kebiasaan baru yang dapat mendukung pembelajaran online dengan lebih produktif.

3. Menyiapkan berkas informed consent yang meminta mahasiswa peserta pelatihan untuk mengikuti pelatihan secara keseluruhan mulai dari awal hingga akhir dan penuh kesungguhan serta berkomitmen untuk mengaplikasikan semua materi yang diperoleh pada perilaku riil sehingga dapat terbentuk kebiasaan baru yang dapat mendukung pembelajaran online dengan lebih produktif.

4. Menyampaikan pelatihan meningkatkan pengelolaan diri (self regulation) agar dapat mengikuti pembelajaran online lebih produktif yang akan disampaikan 4 pertemuan dengan frekuensi 1 minggu 1 pertemuan@120 menit. Dengan urutan kegiatan:

B. Pelaksanaan
Keseluruhan pelaksanaan kegiatan dilakukan dengan platform google meet. Akan diselenggarakan 4 sesi pertemuan. Evaluasi pelaksanaan dilaksanakan per pertemuan. Dilaksanakan 15 menit sebelum pertemuan selesai. Sedangkan evaluasi pelaksanaan pelatihan secara keseluruhan dilakukan pada pertemuan ke 4 .

Pada pertemuan pertama, sebelum disampaikan materi, peserta diberi informasi tentang tujuan diberikan pelatihan. Kemudian dilanjutkan pengisian skala self regulation sebagai pretest. Setelah itu disampaikan materi pertama dengan topik "Kesiapan diri sebelumsaat-setelah mengikuti pembelajaran online". Penyampaian materi secara klasikal untuk semua peserta. Adapun urutan kegiatan yang dilakukan: (1) perkenalan, menggali keluhan dan permasalahan mahasiswa dan apa yang menjadi harapannya; penyampaian materi tentang self regulated learning : konsep, proses, pengaturan emosi); penyampaian materi tentang self regulation learning : pengelolaan kognisi, afeksi, psikomotor. Diakhir pertemuan pertama, peserta diberi tugas rumah: setiap peserta diminta membuat goal setting pencapaian nilai pada satu mata kuliah, didasarkan pada beberapa pertimbangan yaitu potensi diri, jumlah kegiatan non akademik yang diikuti, tingkat kesulitan mata kuliah yang dijadikan target, tugas, kuis, UTS pada mata kuliah tersebut. Selanjutnya diminta pula membuat perencanaan kegiatan 1 hari untuk mencapai goal setting yang telah ditetapkan. Lihat contoh, buat keseimbangan antara tugas akademik-non akademik--rekreasi. Setelah dibuat perencanaan silakan dilaksanakan perencanaan aktivitas 1 tersebut. Lakukan self control dan buat catatan mengapa sebuah aktivitas yang direncanakan dapat dilaksanakan sedangkan ada aktivitas lain yang tidak.

Pertemuan kedua dengan topik "membuat perencanaan aktivitas harian agar dapat mengikuti pembelajaran online lebih produktif'. Aktivitas yang dilakukan: (1)Penyampaian materi tentang Menetapkan Goal Setting; (2)penyampaian materi tentang "Time Management Tips" dan The Eisenhower Decission Matrix"; pemberian tugas rumah untuk membuat perencanaan kegiatan selama 3 hari dalam upaya mencapai goal setting yang telah ditetapkan.

Pertemuan ketiga dengan topik "Evaluasi pelaksanaan perencanaan yang telah dilakukan dan membuat perencanaan aktivitas untuk 1 minggu ke depan". Dilaksanakan dalam kelompok kecil. Peserta dibagi dalam 2 kelompok kecil dibimbing dan difasilitasi oleh dua fasilitator. Dalam kelompok kecil didiskusikan rancangan kegiatan dan time line yang telah dilakukan selama 3 hari, serta dilakukan evaluasi mengapa aktvitas tertentu dapat dilakukan sedangkan aktivitas lain tidak dapat dilakukan. 
Pertemuan keempat dengan topik "Evaluasi pelaksanaan perencanaan yang telah dilakukan dan memotivasi peserta untuk melanjutkan secara mandiri”. Dilaksanakan secara klasikal. Dalam kegiatan ini dilakukan evaluasi terhadap kegiatan yang dilakuan selama 5 hari dalam upaya untuk mencapai goal setting. Dianalisa pula penyebab suatu aktivitas tidak dapat dilakukan dan aktivitas lain dapat dilakukan. Setelah seluruh materi disampaikan pada pertemuan keempat, selanjutnya peserta diminta lagi mengisi skala self regulation sebagai posttes.

Terhadap pre tes dan post tes yang telah diisi peserta selanjutnya dilakukan analisa statistik parametrik, analisis uji paired t-test dengan SPSS versi 21.

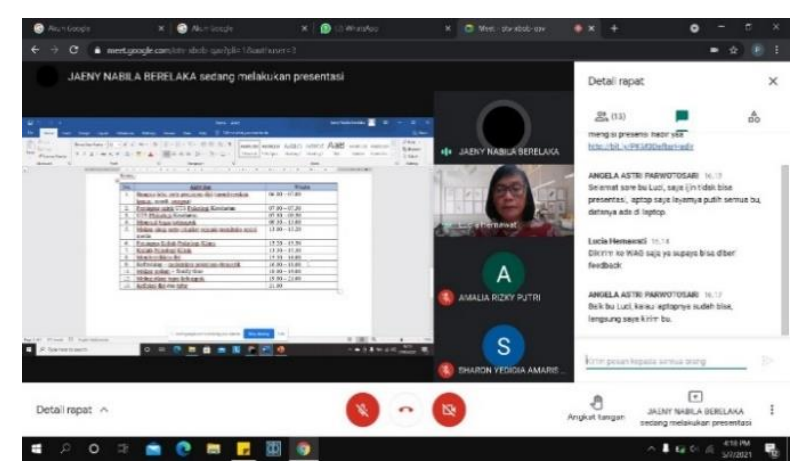

Gambar 1. Paparan materi pelatihan

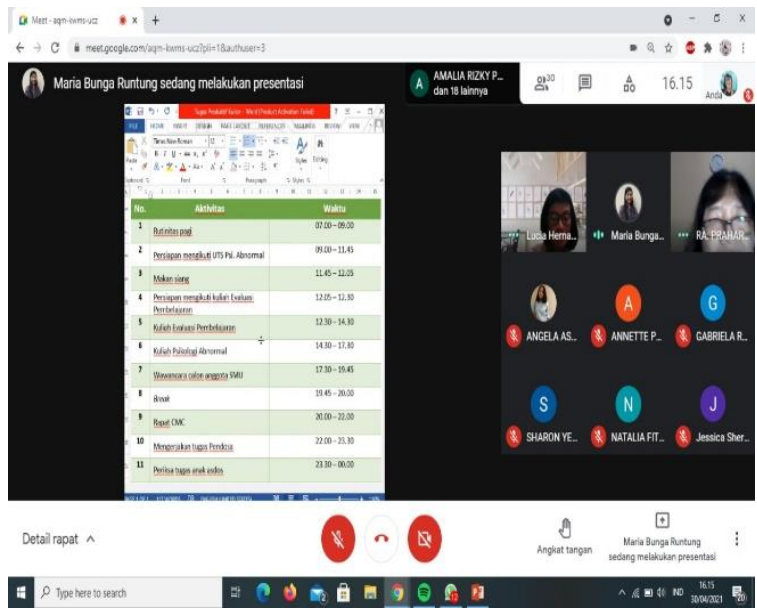

Gambar 2. Presentasi tugas rumah peserta

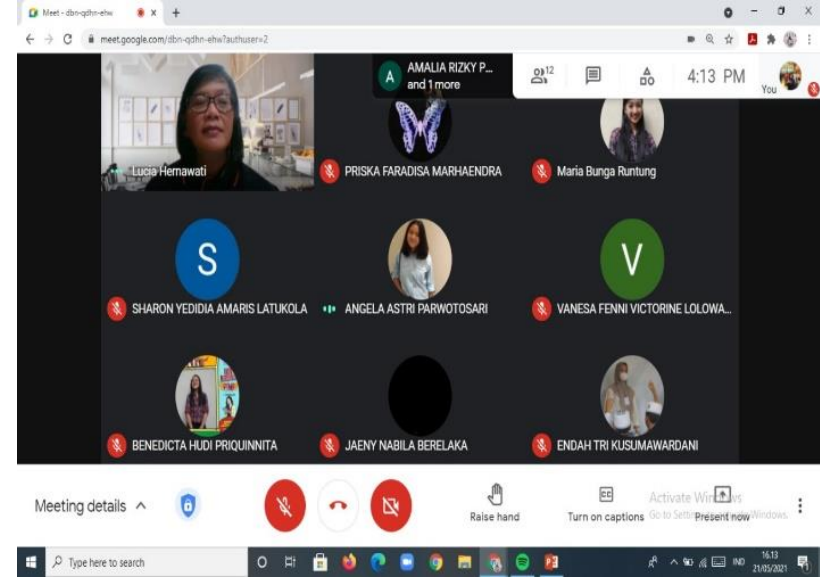

Gambar 3.Sharring peserta

\section{HASIL ANALISIS DATA}

Analisis data yang membandingkan antara data pre tes dan post tes dengan menggunakan statistik parametrik analisis uji paired t-test dengan SPSS versi 21 menunjukkan nilai $\mathrm{t}=1.707(\mathrm{p}>0.05)$ tidak ada perbedaan antara sebelum dan setelah mengikuti pelatihan. Dengan kata lain dapat dikatakan pemberian pelatihan ini tidak meningkatkan selfregulation mahasiswa.

Berdasar hasil evaluasi yang disampaikan secara lisan, mahasiswa peserta pelatihan mengatakan hidupnya lebih tertata, tertantang untuk mencapai target. mood lebih bagus, lebih bersemangat dan lebih mengenal kekuatan maupun kelemahan dirinya, bisa mengelola waktu dan tugasnya dengan lebih baik yaitu dengan membedakan aktivitas mana yang menjadi prioritas dan harus segera diselesaikan dan mana yang bisa ditunda atau bahkan didelegasikan pada orang lain

\section{IV.DISKUSI}

Pengembangan self regulation berangkat dari konsep kognitif behavioural. Pada tahap awal mahasiswa dibekali berbagai penjelasan untuk memahami konsep selfregulation, tahapan yang akan dilewati secara detail, selanjutnya diminta mengaplikasikan pada perilaku nyata [10]. Membuat paham mahasiswa tentang pengembangan self-regulation dan mengaplikasikannya di tengah berbagai kegiatan akademik dan non akademik yang dilakukan bukanlah hal yang mudah. Perlu penyampaian materi dan latihan yang berulang. Mengembangkan selfregulation melibatkan strategi kognitif, regulasi motivasional dan behavioral akademik. Bisa jadi pelatihan yang diberikan hanya empat pertemuan tidak menjangkau 
seluruh aspek regulasi sehingga peningkatan kemampuan self-regulation belum terlihat.

Aplikasi konsep pengembangan self-regulation pada perilaku nyata dibutuhkan waktu 28 hari secara terus menerus tanpa jeda untuk membentuk perilaku baru secara relatif

permanen [11]. Dalam pelaksanaan pelatihan pengembangan self-regulation ini terdapat jeda 4 hari (libur lebaran), tidak bisa dikontrol perilaku mahasiswa. Saat evaluasi di pertemuan ketiga, mahasiswa menceritakan tidak menjalankan perilaku yang direncanakan selama libur lebaran (4 hari). Karena sangat gembira bertemu dengan keluarga besarnya membuatnya lupa pada perilaku yang seharusnya dilakukan. Dengan adanya jeda 4 hari, bisa jadi membuat mahasiswa harus berusaha keras memulai lagi meningkatkan motivasi internalnya. Setelah jeda ini hanya tinggal 1 sesi pertemuan. Tentu tidak mudah mengembalikan komitmen dan motivasi internal seperti sebelumnya. Bisa jadi hal ini membuat peningkatan self regulation tidak terjadi.

Secara lisan disampaikan pada evaluasi bahwa mahasiswa peserta pelatihan memiliki hidupnya lebih tertata, tertantang untuk mencapai target, mood lebih positif, lebih bersemangat dan lebih mengenal kekuatan maupun kelemahan dirinya, bisa mengelola waktu dan tugasnya dengan lebih baik yaitu dengan membedakan aktivitas mana yang menjadi prioritas dan harus segera diselesaikan dan mana yang bisa ditunda atau bahkan didelegasikan pada orang lain setelah mengikuti pelatihan. Hal ini sesuai dengan pendapat Zimmerman $\left(2010^{12}\right)$ bahwa dalam mengembangkan self-regulatian, individu harus memahami kekuatan dan kelemahan diri, memahami apa yang diinginkan dan harus menentukan target yang akan dicapai serta menentukan kegiatan untuk mencapai target yang ditetapkan. Dengan membuat perencanaan dan mengaplikasikannya pada perilaku riil membuat individu memiliki berbagai kegiatan yang dilakukan secara terencana, teratur, dan tertata [12]

\section{KESIMPULAN}

Berdasarkan analisis statistik parametrik, uji paired t-test dengan SPSS versi 21 ditemukan bahwa pemberian pelatihan ini tidak meningkatkan self-regulation mahasiswa. Namun berdasarkan evaluasi yang disampaikan peserta secara verbal, setelah mengikuti pelatihan, mahasiswa merasakan hidupnya lebih tertata, tertantang untuk mencapai target, mood lebih positif, lebih bersemangat dan lebih mengenal kekuatan maupun kelemahan dirinya, bisa mengelola waktu dan tugasnya dengan lebih baik yaitu dengan membedakan aktivitas mana yang menjadi prioritas dan harus segera diselesaikan dan mana yang bisa ditunda atau bahkan didelegasikan pada orang lain. Sehingga dapat disimpulkan ada peningkatan self-regulation pada mahasiswa secara kualitatif walau tidak secara kuantitatif.

\section{Daftar Pustaka}

[1] Maulana, H.A., \& Iswari, R.D. (2020) Analisis Tingkat Stres Mahasiswa Terhadap pembelajaran Daring Pada Mata Kuliah Statistik Bisnis di Pendidikan Vokasi. Jurnal Ilmiah Kependidikan, XIV (1), h. 17-30. Diambil dari http://www.jurnal nasional.ump.ac.id/index.php/khazanah/article/downlo ad/8479/3391.

[2] Firman \& Rahman, S.R. (2020). Pembelajaran Online di Tengah Pandemi Covid-19. Indonesian Journal of Education Science, 02(02), 81-89. Diambl dari https://ojs.unsulbar.ac.id/index.php/ijes/article/downlo ad/659/369.

[3] Nazarudin, A., Chanum, I., \& Marjo, H.K.(2014). "Regulasi Diri Mahasiswa Bimbingan Dan Konseling Dalam Proses Penyusunan Skripsi”. Insight: Jurnal Bimbingan dan Konseling. 3(2), hlm 8-22. DOI: https://doi.org/10.21009/ INSIGHT.032

[4] Ratnafuri, I. \& Muslihati, 2020. Efektivitas Pelatihan Self Regulated Learning dalam Pembelajaran Daring untuk Meningkatkan Ketuntasan Belajar Siswa di Masa Pandemi Covid-19. Prosiding Seminar Bimbingan dan Konseling. http://conference.um.ac.id

[5] Hurlock, E. B. (2003) Psikologi Perkembangan. Suatu Pendekatan Sepanjang Retang Kehidupan. Jakarta : Erlangga.

[6] Zimmerman, B.J. (2000) Attaining Self Regulation. Social Cognitive Perspective. Handbook of Self Regulation. 13-39. New York City : University of New York.

[7] Gestsdottir, S., Lerner, R. M. (2008). "Positive Development in Adolescence: The Development and Role of Intentional Self-Regulation". Journal of Human Development 51, hlm. 202-224. DOI: 10.1159/000135757

[8] Pranoto, H., Atieka, N., Fajarwati, R., \& Septora, R. (2018). "Layanan Bimbingan Kelompok Dengan Teknik Self Regulation untuk Meningkatkan Motivasi Belajar Mahasiswa". Indonesian Journal of Educational Counseling, 2 (1) , hlm 87-112.ISSN 2541-2779 (Print). ISSN 2541-2787. Diperoleh dari https://doi.org/10.30653/001.201821

[9] Marda, S., Sunawan, Kurniawan, K. (2019). "Efektivitas Layanan Penguasaan Konten dan SelfRegulated Learning untuk Menurunkan Prokrastinasi Akademik" Indonesian Journal of Guidance and Counseling: Theory and Application 8(2), hlm 212223. Diperoleh dari http://journal.unnes.ac.id/sju/ index.php/jbk 
[10] Boekaerts, M., Pintrich, P., \& Zeidner, M. (2000).

Handbook of Self Regulation.California,

USA:AcademicPress

[11] Maltz, M. (2015). The New Pscycho-Cybernetics.

USA: Tarcher Perigee

[12] Zimmerman, B. J. (2010). "Becoming A Self

Regulated Lerner: An Overview”. Theory Into Practice, 41

(2), hlm. 64-70. DOI: 10.1207/s15430421tip4102_2 